\title{
Effects of Continuous Positive Airway Pressure on Pulmonary Function and Blood Gases of Infants with Respiratory Distress Syndrome
}

\author{
C. PETER RICHARDSON ${ }^{(31)}$ AND A. L. JUNG \\ Division of Neonatology, Department of Pediatrics, University of Utah School of Medicine, Salt Lake City, Utah, \\ USA
}

\section{Summary}

Nitrogen washout measurements and blood-gas analyses were made on 32 newborn infants with severe RDS at continuous positive airway pressures (CPAP) of 5,10 , and $15 \mathrm{~cm} \mathrm{H}_{2} \mathrm{O}$. Increases in airway pressure resulted in significant increases in $\mathrm{PaO}_{2}$ and functional residual capacity (FRC). It also produced significant decreases in alveolar turnover rates of the "fast" and "slow" alveolar spaces of a two-space lung model. Changes in CPAP did not significantly affect the distribution of ventilation.

The changes in $\mathrm{PaO}_{2}$, due to changes in CPAP, did not correlate well with changes in $\mathrm{FRC} / \mathrm{wt}$ nor with changes in alveolar turnover rates. Thus, the effects of increasing CPAP on $\mathrm{PaO}_{2}$ were not simply due to increases in FRC. The changes in $\mathrm{PaO}_{2}$ are due to a complex relationship between changes in FRC, alveolar turnover rates, and to other alterations in cardiopulmonary function that are yet to be fully understood.

\section{Speculation}

Results from this study show that large portions of the lung have alveolar turnover rates below normal. Increasing airway pressures could lead to decreases in the rate of pulmonary perfusion and to an improvement in the ventilation-perfusion ratio of these alveolar units. This could partially account for the observation that increases in CPAP generally produce increases in $\mathrm{PaO}_{2}$.

$\operatorname{CPAP}(4,12)$ has become a mainstay of therapy in the treatment of newborn infants with RDS. In order to optimally manage these infants the clinician needs to know the effects of this therapy on cardiopulmonary function. Infants with RDS placed on continuous distending pressures (CDP) usually have increases in FRC (3), decreases in dynamic lung compliance $(3,28)$, and increases in $\mathrm{PaO}_{2}(3,5,7,8,12,20,21,28)$. Unfortunately, the incidence of pneumothorax may be higher in infants on CPAP $(6,13,19,27)$ and increased thoracic pressures can cause decreases in cardiac output and oxygen transport $(16,25)$. In our study we investigated the effects of CPAP level on FRC, distribution of ventilation, and alveolar turnover rates. We then attempted to correlate these parameters with changes in arterial blood gases. Techniques used were limited to noninvasive methods.

\section{METHODS AND MATERIAL} SUBJECTS

Measurements were made on 32 newborn infants with severe RDS. Clinical diagnoses were made on the bases of tachypnea, cyanosis, intercostal retractions, expiratory grunting, and radiographs consistent with classic RDS (2). All infants were intubated after failing to maintain $\mathrm{PaO}_{2}$ of $60 \mathrm{~mm} \mathrm{Hg}$ while breathing $\mathrm{FiO}_{2}$ of 0.6 or greater. Mean and SE of gestational age and weight of the infants were $33.7 \pm 0.4 \mathrm{wk}$ and $2013 \pm 93 \mathrm{~g}$. Some infants were studied several times during the course of their disease so that 52 sets of data were gathered at infant postnatal ages ranging from 4 to $152 \mathrm{~h}$ (mean $38 \mathrm{~h}$ ). Four of the infants required mechanical ventilation due to the inability to maintain $\mathrm{PaO}_{2}$ of 60 $\mathrm{mm} \mathrm{Hg}$ with airway pressure greater than $15 \mathrm{~cm} \mathrm{H}_{2} \mathrm{O}$ and $\mathrm{FiO}_{2}$ of 1.0. Three of these four infants died of intraventricular hemorrhages. A fourth infant died of necrotizing enterocolitis. All four infants that died also had pneumothoraces, and were the only infants with pneumothoraces.

\section{EQUIPMENT}

Open circuit nitrogen washout techniques were used to determine FRC, alveolar ventilation $\left(\dot{\mathrm{V}}_{\mathrm{A}}\right)$, distribution of ventilation, and alveolar turnover rates. Respiratory nitrogen concentrations were measured by placing the Nitralyzer (model 391 nitrogen analyzer, Warren E. Collins, Inc., Braintree, MA) needle of the pickup head directly in the endotracheal tube; thus, the nitrogen signal to recording delay was only $15 \mathrm{msec}$ for $90 \%$ response. Flow rates of respiration were measured by a heated Fleisch " 00 " pneumotachometer (Instrumentation Association, Inc., New York, NY)' and integrated electronically (IC-RESP respiratory flow rate integrator, Gilson Medical Electronics, Inc., Middleton, WI) to obtain tidal volumes. The logarithmic output of the nitrogen analyzer and exhaled tidal volumes were recorded on an X-Y plotter (model 815 X-Y recorder, MFE Corp., Salem, NH). Calculations of $\dot{V}_{A}$ and FRC and multiple space curve analyses were made directly on the recorded $\mathrm{X}-\mathrm{Y}$ washout traces.

\section{PROCEDURES}

The equipment was calibrated before each nitrogen washout test. Two gases of known concentration, air and $1.7 \%$ nitrogen in oxygen, were used to calibrate the nitrogen analyzer. A $30-\mathrm{ml}$ glass syringe was used to supply a known volume of air for calibrating the pneumotachometer. Inhalation and exhalation tidal volumes were compared and only infants with negligible leakage around their endotracheal tubes were studied. Often infants breathed irregularly during the course of nitrogen washout; these data were discarded and tests rerun. Immediately before each nitrogen washout $0.45 \mathrm{ml}$ blood was sampled from the infant's umbilical artery catheter and analyzed for $\mathrm{pH}, \mathrm{PaCO}_{2}$, and $\mathrm{PaO}_{2}$ (Radiometer BMS-3 blood gas analyzer, The London Company, Westlake, $\mathrm{OH})$. To initiate the washout the infant's $\mathrm{FiO}_{2}$ was switched to 1.0. Washouts were considered complete when end-expired concentrations were $1 / 40$ th the initial nitrogen concentration; this matches washout gradients from room air $(80 \%)$ to $2 \%$. Three to $5 \mathrm{~min}$ were required to complete the washout. After each washout, $15 \mathrm{~min}$ were allowed for the lungs to reequilibrate with the initial $\mathrm{FiO}_{2}$ before retesting was done. The blood-gas and nitrogen washout measurements were made 
while the infant's airway pressures were adjusted to 5,10 , and 15 $\mathrm{cm} \mathrm{H}_{2} \mathrm{O}$. The order of pressure selection was arbitrary.

\section{DATA ANALYSES}

The FRC was calculated from the nitrogen washout traces by integrating the volume of nitrogen exhaled (23). Integrations of the first three breaths were used to measure an average anatomic dead space to tidal volume ratio $\left(\mathrm{V}_{\mathrm{D}} / \mathrm{V}_{\mathrm{T}}\right)(9,14)$. This ratio was assumed to be the same for the remainder of the washout. The FRC was then calculated from $V_{D} / V_{T}$, the mean tidal volume $\left(\bar{V}_{T}\right)$ for the test period, and the summation of the end-tidal nitrogen concentrations. The respiratory rate, $\bar{V}_{T}$, and $V_{D} / V_{T}$ were then used to calculate alveolar ventilation. Anatomic dead space values used in these calculations should not be confused with the physiologic dead space values frequently used to calculate "effective" alveolar ventilation. The accuracy of the method used and derivations of the mathematic equations are contained in the Appendix.

The nitrogen washout curves were corrected for nitrogen elimination from the blood and tissues (24) and then multiple space mathematic models $(10)$ were fit to the curvature to obtain alveolar turnover rates. A modification of the nitrogen clearance delay (10), the inspired gas distribution index (IDI) (14), was used to evaluate the uniformity of ventilation (see Appendix for definition of IDI).

In the statistical analyses of these data, paired $t$-tests were used (15). Probability values of $P<0.05$ were considered significant.

\section{RESULTS}

Table 1 lists the mean values of blood gas and ventilatory parameters that were not significantly affected by CPAP level. A trend towards decreases in alveolar ventilation and minute ventilation $\left(\dot{\mathrm{V}}_{\min }\right)$ along with an increase in $\mathrm{PaCO}_{2}$ were observed as CPAP was raised, but these changes did not reach statistical significance.

Increases in CPAP caused significant changes in $\mathrm{PaO}_{2}, \mathrm{FRC}$, and alveolar turnover rates. Figure 1 demonstrates the relatively linear relationships between increases in mean $\mathrm{PaO}_{2}$, mean FRC/wt, and CPAP. The curvature of the nitrogen washout traces

Table 1. Blood gas and ventilatory parameters not significantly $(P$ $>0.1)$ affected by CPAP level

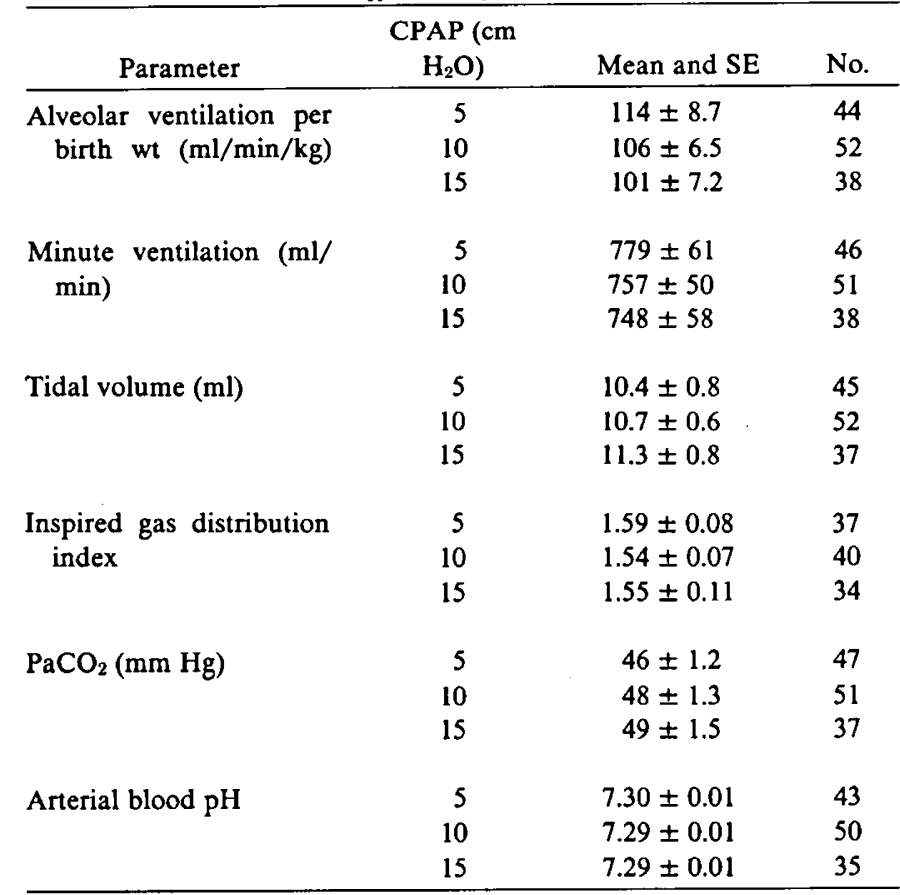

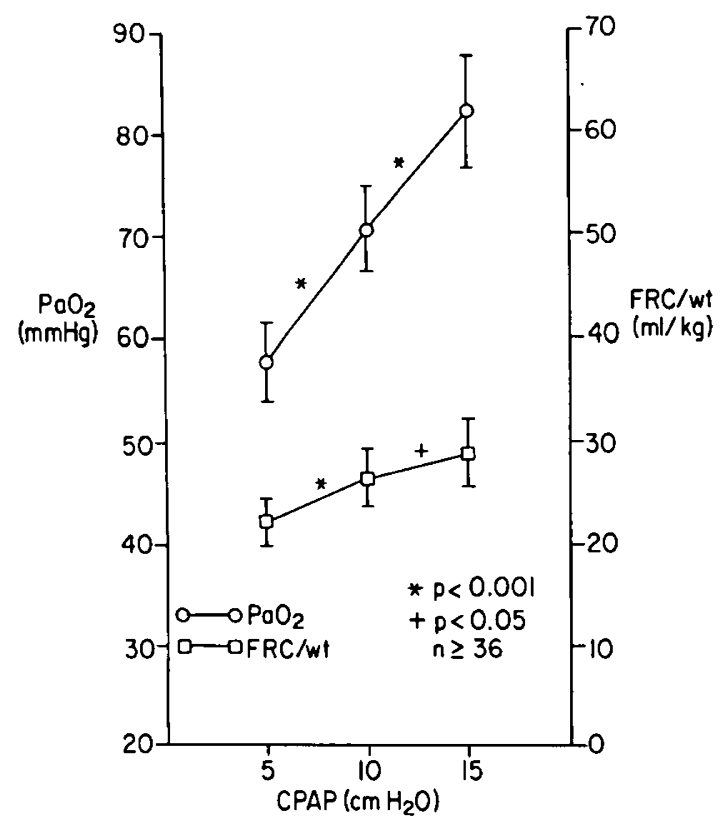

Fig. 1. Mean values $\pm \mathrm{SE}$ of arterial oxygen tension and functional residual capacity per birth weight of infants at three levels of CPAP.

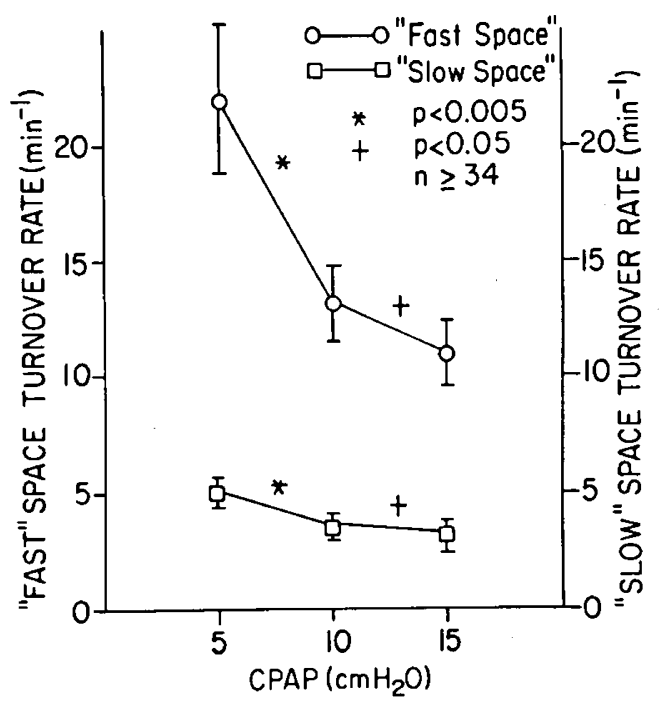

Fig. 2. Mean value \pm SE of "fast space" and "slow space" turnover rates at three levels of CPAP.

(end-tidal values) were well represented by a two-space mathematic model giving "fast" and "slow" ventilatory spaces. Figure 2 shows the decreases in alveolar turnover rates of the two spaces that occurred with increases in CPAP. Larger decreases were observed when CPAP was raised from 5 to $10 \mathrm{~cm} \mathrm{H}_{2} \mathrm{O}$ than when raised from 10 to $15 \mathrm{~cm} \mathrm{H}_{2} \mathrm{O}$.

Attempts were made to correlate changes in $\mathrm{PaO}_{2}$ caused by CPAP increases with the changes in $\mathrm{FRC} / \mathrm{wt}$, and with changes in alveolar turnover rates. Both correlations were poor $(r<0.3)$. The linear correlation between $\mathrm{PaO}_{2}$ and $\mathrm{FRC}$, independent of CPAP, was significant $(P<0.001, n=107)$ but also poor $(r=$ 0.43).

The infant's FRC did not always increase as airway pressures were increased. Of the 81 pairings of measurements, where CPAP was either raised from 5 to $10 \mathrm{~cm} \mathrm{H}_{2} \mathrm{O}$ or from 10 to $15 \mathrm{~cm} \mathrm{H}_{2} \mathrm{O}$, there were 25 instances where FRC values either stayed the same (4) or slightly decreased (21). In 16 of these 25 instances (20\% of the 81 increases in CPAP) the $\mathrm{PaO}_{2}$ increased even though the FRC decreased. 
The $\mathrm{PaO}_{2}$ did not always increase when the $\mathrm{FRC}$ increased with the elevations in airway pressure. These decreases in $\mathrm{PaO}_{2}$ occurred in 8 of the 81 pairings (10\%). In all of these instances the $\mathrm{PaCO}_{2}$ also increased.

The data from the infants were catagorized into three groups according to postnatal age: 1) infants studied at less than $12 \mathrm{hr}$ of age, 2) greater than $12 \mathrm{hr}$ but less then $48 \mathrm{hr}$, and 3) greater than $48 \mathrm{hr}$ of age. These age ranges were somewhat arbitrarily chosen to classify the infants into different phases of diseased state. Statistical analyses of the data indicated that the effects of CPAP level on $\mathrm{PaO}_{2}$ and FRC were not different for the infants in the various age groupings. Other age groupings were also investigated but the results were the same; there were no differences. However, it is interesting to note that in the instances where raising CPAP caused increases in FRC and $\mathrm{PaCO}_{2}$ and decreases in $\mathrm{PaO}_{2}$ the infants were all under $16 \mathrm{hr}$ (three infants) or more than $53 \mathrm{hr}$ of age (five infants).

Three of the four infants that required mechanical ventilation had FRC and $\mathrm{PaO}_{2}$ responses to CPAP increases that were within $1 \mathrm{SD}$ of the mean response. The fourth infant's response was less than 1 SD from the mean, yet this infant survived whereas the other three infants died.

\section{DISCUSSION}

The insignificant affect of CPAP on $\mathrm{PaCO}_{2}$ and $\mathrm{pH}$ is in accord with the results of other investigators $(3,7,12)$. However, it is important to consider the changes in $\mathrm{PaCO}_{2}$ in instances where increases in CPAP caused the FRC to increase but the $\mathrm{PaO}_{2}$ to decrease. In all of these instances $\mathrm{PaCO}_{2}$ values increased. This is an indication of decreased alveolar ventilation which may have been due to alveolar overdistention.

The uniformity of ventilation was statistically unaffected by CPAP levels studied; however, IDI values were less than those reported for term infants (14). This is surprising because infants with RDS not treated with CPAP generally have a less uniform distribution of ventilation than term infants (17). Decreases in airway resistance (22) could account for an improved uniformity of ventilation. Since the airways of newborn infants are relatively compliant, decreases in airway resistance would probably be realized at low levels of CPAP. Another possibility is that CPAP may be preventing actual airway closure during exhalation (18).

The poor correlation between changes in $\mathrm{PaO}_{2}$ and $\mathrm{FRC} / \mathrm{wt}$ measured at the different CPAP levels is consistent with the results reported of infants "on" and "off" CDP (3). The correlation of our $\mathrm{PaO}_{2}$ and $\mathrm{FRC} /$ wt data at different levels of CPAP was weakened by two groups of infants: 1) the instances of apparent alveolar overdistention, and 2) the instances where FRC decreased at increased airway pressures, yet the $\mathrm{PaO}_{2}$ still increased. These decreases in FRC could have been caused by forced exhalations which may be a reflex action. This type of breathing could lead to increased thoracic pressures and decreased pulmonary blood flow. Decreasing alveolar capillary blood flow to the slowly ventilated lung space would improve the ventilation-perfusion ratio of that space and improve $\mathrm{PaO}_{2}$. However, the end result may not be advantageous to the infant because decreased cardiac output can also lead to decreased oxygen transport $(16,25)$. An additional consideration would be that CPAP caused decreases in true right to left shunting through fetal pathways. But preliminary results of Gregory et al. (11) indicate that CPAP does not alter right to left shunting through the ductus arteriosus. This, of course, does not preclude the possibility of shunting at the intracardiac level.

"Fast space" alveolar rates at $5 \mathrm{~cm} \mathrm{H}_{2} \mathrm{O}$ CPAP were almost 3 times higher than those reported for term infants (17). These turnover rates are indicative of hyperventilation, or areas of the lung with high ventilation-perfusion ratios (26), and could result in dead space ventilation (1). Increasing CPAP reduced "fast space" turnover rates toward normal values. This reduction coupled with increases in FRC may well account for the $\mathrm{PaO}_{2}$ improvements observed.

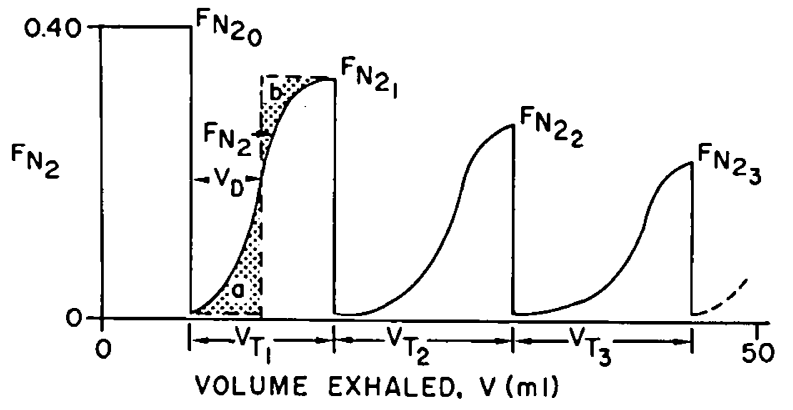

Fig. 3. Expanded nitrogen washout recording used in anatomic dead space measurements.

\section{CONCLUSION}

The major rationale for using CPAP in infants with RDS has been to overcome atelectasis by balancing high alveolar surface tensions, thereby decreasing intrapulmonary shunting and increasing arterial oxygenation (12). Our study only partially supports this rationale. Increases in CPAP generally cause increases in FRC and $\mathrm{PaO}_{2}$, but correlations between these parameters were poor. Increases in CPAP also cause reductions in "fast space" alveolar turnover rates toward normal values, but this did not correlate well with changes in $\mathrm{PaO}_{2}$ either. Infants on CPAP in this study had more even distribution of ventilation than the values of a previous study of infants not on CPAP; however, this parameter was unaffected by the different CPAP levels studied and therefore cannot account for the increase in $\mathrm{PaO}_{2}$ observed. Thus, we conclude that the mechanisms of action of CPAP on the $\mathrm{PaO}_{2}$ of infants with RDS are very complex and should be studied further. We also conclude that measurements of FRC, in conjunction with blood gas analyses, can be used to alert the clinician to those instances where increases in CPAP cause decreases in FRC and the occasional instances of gross alveolar overdistention.

\section{APPENDIX}

\section{DERIVATION OF MATHEMATIC EQUATIONS AND EVALUATION OF} NITROGEN WASHOUT TECHNIQUES

Alveolar ventilation is calculated from the anatomic dead space $\left(V_{D}\right)$, tidal volume $\left(V_{T}\right)$, and breath rate $(f)$. The equation for calculating $V_{D}$ is obtained by setting area a of Figure 3 equal to area $b(9)$.

$$
\begin{gathered}
\text { Area } a=\int_{0}^{\mathrm{V}} \mathrm{FN}_{2} \mathrm{dV} \\
\text { Area } \mathrm{b}=\mathrm{FN}_{2_{1}}\left(\mathrm{~V}_{\mathrm{T}}-\mathrm{V}_{\mathrm{D}}\right)-\int_{\mathrm{V}_{\mathrm{D}}}^{\mathrm{V}_{\mathrm{T}_{1}}} \mathrm{FN}_{2} \mathrm{dV} \\
\int_{0}^{\mathrm{V}} \mathrm{FN}_{2} \mathrm{dV}=\mathrm{FN}_{\mathrm{2}_{1}}\left(\mathrm{~V}_{\mathrm{T}}-\mathrm{V}_{\mathrm{D}}\right)-\int_{\mathrm{V}_{\mathrm{D}}}^{\mathrm{V}_{T_{1}}} \mathrm{FN}_{2} \mathrm{dV} \\
\mathrm{V}_{\mathrm{D}}=\mathrm{V}_{\mathrm{T}}-\frac{1}{\mathrm{FN}_{2_{1}}} \int_{0}^{\mathrm{V}_{T_{1}}} \mathrm{FN}_{2} \mathrm{dV}
\end{gathered}
$$

Equation 1 can be used to find the average anatomic dead space $\left(\bar{V}_{D}\right)$ for the first three breaths. The average tidal volume $\left(\overline{\mathrm{V}}_{\mathrm{T}}\right)$ can be calculated for $\mathrm{m}$ breaths, the number required to reduce the end-expired nitrogen concentration to $1 / 40$ th the original concentration.

$$
\overline{\mathrm{V}}_{\mathrm{T}}=\frac{1}{\mathrm{~m}} \sum_{\mathrm{i}=1}^{\mathrm{m}} \mathrm{V}_{\mathrm{T}_{\mathrm{i}}}
$$

Then the alveolar ventilation is calculated using equations 1 and 2 in

$$
\dot{V}_{A}=\left(V_{T}-V_{D}\right) f
$$


The FRC is equal to the volume of the nitrogen washed out of the lungs divided by the initial fraction of nitrogen in the lungs, $\mathrm{FN}_{2_{0}}$. The volume of nitrogen $\left(\mathrm{VN}_{2_{\mathrm{i}}}\right)$ exhaled during each breath of washout is

$$
\mathrm{VN}_{\mathrm{Z}_{\mathrm{i}}}=\int_{\mathrm{V}_{\mathrm{T}_{\mathrm{i}-1}}}^{\mathrm{V}_{\mathrm{T}}} \mathrm{FN}_{2} \mathrm{dV}
$$

This volume summed for $\mathrm{m}$ breaths and divided by $\mathrm{FN}_{20}$ is the FRC

$$
F R C=\frac{1}{F N_{2, i}} \sum_{i=1}^{m} \int_{V_{T_{i-1}}}^{V_{T_{i}}} F_{2} d V
$$

but from Equation 1 the sum of the integrals can be replaced by the sum of the end-tidal nitrogen fraction, $\mathrm{FN}_{2 \mathrm{i}}$. Therefore,

$$
F R C=\left(\frac{V_{T}-V_{D}}{F_{2_{0}}}\right) \sum_{i=1}^{m} F_{2_{i}}
$$

These end-tidal values are easily taken from the washout traces.

The validity of using Equation 3 to calculate FRC was checked by conducting nitrogen washout tests on a mechanical model. A glass syringe simulated an alveolar volume of $20 \mathrm{ml}$ and the addition of $1.6 \mathrm{ml}$ dead space made the FRC $21.6 \mathrm{ml}$. Tidal volumes of 5 and $10 \mathrm{ml}$ were used on 13 washout tests and the mean $\pm \mathrm{SE}$ of the measured FRC was $21.3 \mathrm{SE} \pm 0.47 \mathrm{ml}$. These measured mean values are only $1 \%$ less than the actual values. The accuracy could be increased by increasing the number of breaths (m) analyzed.

Reproducibility of FRC measurements was evaluated using the results of multiple determinations made on five infants with RDS. The mean difference in percentage of 44 measurements of FRC was 7.4 SE \pm 1.0 . This is consistent with the accuracy of conventional nitrogen washout methods (24).

Considering the accuracy of the mechanical model results and the good reproducibility on infants we believe that this is a valid technique for obtaining FRC in infants with RDS on CPAP.

\section{INSPIRED GAS DISTRIBUTION INDEX (IDI)}

Hanson and Shinozaki (14) showed that in cases of even distribution of ventilation the alveolar nitrogen concentration during nitrogen washout is related to the volume of alveolar ventilation $\left(\mathrm{V}_{\mathrm{A}}\right)$ by

$$
\ln \left[\mathrm{FN}_{2}(\mathrm{t}) / \mathrm{FN}_{2_{0}}\right]=\mathrm{V}_{\mathrm{A}}(\mathrm{t}) / \mathrm{FRC}
$$

During washout, if the alveolar nitrogen is reduced from 80 to $2 \%$ :hen $\mathrm{V}_{\mathrm{A}}=3.69$ FRC; a linear relationship.

They then defined IDI $=\mathrm{V}_{\mathrm{A}}^{\prime} /(3.69 \mathrm{FRC})$, where $\mathrm{V}_{\mathrm{A}^{\prime}}$ is the volume of alveolar ventilation required to reduce the alveolar nitrogen concentration to $1 / 40$ th its initial concentration.

\section{REFERENCES AND NOTES}

1. Auld, P. A. M.: Concepts in pulmonary physiology. In: E. M. Scarapelli: Pulmonary Physiology of the Fetus, Newborn and Child, p. 28 (Lea \& Febiger, Philadelphia, 1975).

2. Auld, P., Hodson, A., and Usher, R.: Hyaline membrane disease: A discussion. Fetal Neonatal Med., 80: 129 (1972).

3. Bancalari, E., Garcia; O. L., and Jesse, M. J.: Effects of continuous negative pressure on lung mechanics in idiopathic respiratory distress syndrome. Pediatrics, 51: 485 (1973).
4. Barach, A. L., Martin, J., and Eckman, M.: Positive pressure respiration and its application to the treatment of acute pulmonary edema. Ann. Intern. Med., 12: 754 (1938).

5. Baum, J. D., and Roberton, N. R. C.: Distending pressure in infants with respiratory distress syndrome. Arch. Dis. Childhood, 49: 771 (1974).

6. Berg, T. J., Pagtakhan, R. D., Reed, M. H., Langston, C., and Chernick, V.: Bronchopulmonary dysplasia and lung rupture in hyaline membrane disease: Influence of continuous distending pressure. Pediatrics, 55: 51 (1975).

7. Chernick, V., and Vidyasagar, D.: Continuous negative chest wall pressure in hyaline membrane disease: One year experience. Pediatrics, 49: 753 (1972).

8. Fanaroff, A. A., Cha, C. C., Sosa, R., Crumrine, R. S., and Klaus, M. H.: Controlled trial of continuous negative external pressure in the treatment of severe respiratory distress syndrome. J. Pediat., 82: 921 (1973).

9. Fowler, W. S.: Lung function studies. II. The respiratory dead space. Amer. J. Physiol., 154: 405 (1948).

10. Fowler, W. S., Cornish, E. R., Jr., and Kety, S. S.: Lung function studies. VIII. Analysis of alveolar ventilation by pulmonary $\mathrm{N}_{2}$ clearance curves. J. Clin. Invest., 31: 40 (1952).

11. Gregory, G. A., Kitterman, J. A., Phibbs, R. H., Schlueter, M. A., and Tooley, W. H.: Increase in lung volume and absence of right to left ductal shunt with continuous positive airway pressure in idiopathic respiratory distress syndrome [Abstr.]. Pediat. Res., 6: 409 (1972).

12. Gregory, G. A., Kitterman, J. A., Phibbs, R. H., Tooley, W. H., and Hamilton, W. K.: Treatment of the idiopathic respiratory-distress syndrome with continuous positive airway pressure. New Engl. J. Med., 284: 1333 (1971).

13. Hall, R. T., and Rhodes, P. G.: Pneumothorax and pneumomediastinum in infants with idiopathic respiratory distress syndrome receiving continuous positive airway pressure. Pediatrics, 55: 493 (1975).

14. Hanson, J. S., and Shinozaki, T.: Hybrid computer studies of ventilatory distribution and lung volume. 1. Normal newborn infants. Pediatrics, 46: 900 (1970).

15. Huntsberger, D. V., and Leaverton, P. E.: Statistical inference. In: The Biomedical Sciences, p. 135 (Allyn and Bacon, Inc., Boston, 1970).

16. Lutch, J. S., and Murray, J. F.: Continuous positive-pressure ventilation: Effects on systemic oxygen transport and tissue oxygenation. Ann. Intern. Med., 76: 193 (1972).

17. Nelson, N. M., Prod'hom, L. S., Cherry, R. B., Lipsitz, P. J., and Smith, C. A.: Pulmonary function in the newborn infant: the alveolar-arterial oxygen gradient. J. Appl. Physiol., 18: 534 (1963).

18. Nelson, N. M., Jr., Smith, C. A., and Nelson, N. M.: The physiology of the newborn infant, 4th Edition, p. 221 (Charles C Thomas, Springfield, IL, 1976).

19. Ogata, E. S., Gregory, G. A., Kitterman, J. A., Phibbs, R. H., Tooley, W. H.: Pneumothorax in the respiratory distress syndrome: Incidence and effect on vital signs, blood gases and $\mathrm{pH}$. Pediatrics, 58: 177, (1976).

20. Outerbridge, E. W., Roloff, D. W., and Stern, L.: Continuous negative pressure in the management of severe respiratory distress syndrome. J. Pediat., 81: 384 (1972).

21. Rhodes, P. G. and Hall, R. T.: Continuous positive airway pressure delivered by face mask in infants with the idiopathic respiratory distress syndrome: A controlled study. Pediatrics, 52: 1/17 (1973).

22. Saunders, R. A., Milner, A. D., and Hopkin, I. E.: The effects of continuous positive airway pressure on lung mechanics and lung volumes in the neonate. Biol. Neonate, 29: 178 (1976).

23. Shinozaki, T., Abajian, J. C., Jr., Tabakin, B. S., and Hanson, J. S.: Theory and clinical application of a digital nitrogen washout computer. J. Appl. Physiol., ? 21: 202 (1966).

24. Strang, L. B., and McGrath, M. W.: Alveolar ventilation in normal newborn infants studied by air wash-in after oxygen breathing. Clin. Sci., 23: 129 (1962).

25. Suter, P. M., Fairley, H. B., and Isenberg, M. D.: Optimum end-expiratory airway pressure in patients with acute pulmonary failure. New Engl. J. Med., 292: 284 (1975).

26. Tori, C. A., Krauss, A. N., and Auld, P. A. M.: Serial studies of lung volume and $\dot{V} A / Q$ in hyaline membrane disease. Pediat. Res., 7: 82 (1973).

27. Yui, V. Y. H., Liew, S. W., and Roberton, N. R. C.: Pneumothorax in the newborn: Changing pattern. Arch. Dis. Childhood, 50: 449 (1975).

28. Yu, V. Y. H., and Rolfe, P.: Effect of continuous positive airway pressure breathing on cardiorespiratory function in infants with respiratory distress syndrome. Acta Paediat. Scand., 66: 59 (1977).

29. Informed consent was obtained from the parents of each patient prior to their being studied.

30. This research was supported by Research Grant 6-23 from the National Foundation-March of Dimes.

31. Requests for reprints should be addressed to: Dr. C. Peter Richardson, Department of Pediatrics, University of Utah Medical Center, 50 North Medical Drive, Salt Lake City, Utah 84132 (USA).

32. Received for publication May 10, 1977.

33. Accepted for publication September 21, 1977. 